\title{
EDUKASI DAN PELATIHAN PEMANFAATAN TEKNOLOGI INFORMASI UNTUK IBU-IBU PKK DESA JATI BARU
}

\author{
Wira Apriani, Nuraisana, Ellisa Purba \\ STMIK Pelita Nusantara, Indonesia \\ wiraaprianii@gmail.com
}

\begin{abstract}
Community service is one of the mandatory things done by a lecturer to carry out the tri darma of higher education, for that a lecturer is required to be more concerned with the community, what problems and what solutions are offered to overcome these problems through research and community service, one of the problems found through the author's observations, there is a lack of knowledge about the use of computers, smartphones and the internet by PKK mothers in Jati Baru Village, even their children are more proficient in using it so that their children use computers, smartphones and the internet without supervision, besides the need to educate how to get profit finance through the internet and social media and gain knowledge about ethics in social media and the internet and understand the general concept of information law and electronic transactions in order to be wise in using the internet.
\end{abstract}

Keywords: Education; Information technology training and use; PKK mothers;

\begin{abstract}
Abstrak
Pengabdian kepada masyrakat adalah salah satu hal wajib yang dilakukan oleh seorang dosen untuk menjalankan tri darma perguruan tinggi untuk itu seorang dosen diwajibkan lebih peduli dengan masyarakat masalah apa dan solusi apa yang ditawarkan untuk mengatasi masalah tersebut melalui penelitian dan pengabdian masyarakat, salah satu masalah yang ditemukan melalui observasi penulis adalah kurangnya pengetahuan tentang penggunaan komputer, smartphone dan internet oleh ibu-ibu PKK di Desa Jati Baru bahkan anak mereka lebih cakap dalam menggunakan hal tersebut sehingga anak mereka menggunakan komputer, smartphone dan internet tanpa pengawasan, selain itu perlunya mengedukasi cara mendapat keuntungan financial melaui internet dan sosial media serta mendapatkan pengetahuan tentang beretika dalam sosial media dan internet dan memahami konsep umum undang-undang informasi dan transaksi elektronik agar bijak dalam menggunakan internet.
\end{abstract}

Kata Kunci: Edukasi; Pelatihan dan pemanfaatan teknologi informasi; Ibu-Ibu PKK;

Submitted: 2020-09-09 Revised: 2020-09-27 Accepted: 2020-09-30

\section{Pendahuluan}

Desa jatibaru berlokasi di Kecamatan pagar merbau kabupaten sumatera utara kabupaten deli serdang. Pendidikan nonformal sebagai salah satu jalur dalam sistem pendidikan nasional yang memiliki peranan penting dalam memberikan layanan pendidikan bagi masyarakat. Karena masyarakat tentunya sangat membutuhkan dan merupakan upaya pemberdayaan masyarakat untuk meningkatkan kemampuan masyarakat agar dapat berkembang sesuai dengan keterampilan yang akan ia miliki. Menurut Sudjana (2004:44) pendidikan luar sekolah adalah, Setiap usaha pelayanan pendidikan luar sistem sekolah, berlangsung seumur hidup, dijalankan dengan sengaja, teratur dan berencana yang bertujuan mengaktualisasi potensi manusia (sikap, tindak dan karya) sehingga dapat terwujud manusia seutuhnya yang gemar belajar dan mampu meningkatkan taraf hidupnya. 
Penyuluhan adalah untuk memberdayakan masyarakat. Memberdayakan berarti memberi daya kepada yang tidak berdaya dan atau mengembangkan daya yang sudah dimiliki menjadi sesuatu yang lebih bermanfaat bagi masyarakat yang bersangkutan. Margono Slamet (2000) menekankan esensi penyuluhan sebagai kegiatan pemberdayaan masyarakat yang telah mulai lazim digunakan oleh banyak pihak sejak Program Pengentasan Kemiskinan pada awal dasawarsa 1990-an. Penyuluhan pembangunan sebagai proses pemberdayaan masyarakat, memiliki tujuan utama yang tidak terbatas pada terciptanya "better-farming, better business, dan better living, tetapi untuk memfasilitasi masyarakat (sasaran) untuk mengadopsi strategi produksi dan pemasaran agar mempercepat terjadinya perubahan-perubahan kondisi sosial, politik dan ekonomi sehingga mereka dapat (dalam jangka panjang) meningkatkan taraf hidup pribadi dan masyarakatnya.

Berdasarkan permasalahan yang dihadapi oleh warga jati baru, maka tujuan dari pengabdian kepada masyarakat ini adalah, Memberikan edukasi dan pengetahuan untuk ibu-ibu PKK berupa teori komputer, smartphone dan penggunaan internet agar bisa mengontrol dan mengawasi kegiatan anak-anak mereka dalam menggunakan komputer, smartphone dan penggunaan internet. Memberikan Pengetahuan dan Meningkatkan kemampuan PKK dalam memanfaatkan sosial media untuk membangun ekonomi kreatif dengan cara promosi dan berniaga di media sosial. Memberikan edukasi dan Meningkatkan pengetahuan ibu-ibu PKK tentang etika bersosial di media sosial dan berinternet dan memahami konsep undang-undang informasi dan transaksi electronik (UU ITE).

\section{Metode}

Pelaksanaan kegiatan pengabdian yang berupa Bentuk kegiatan dari pengabdian kepada masyarakat ini adalah dengan cara praktik dan presentase langsung dengan ibuibu PKK dan tidak hanya topik bahasan yang di jelaskan oleh tutor akan tetapi juga didahului dengan kemajuan teknologi industry 4.0 pentingnya pendidikan komputer di era saat ini bagi anak-anak mereka dan juga motivasi yang membangun semangat.. Beberapa persiapan sebelum pelaksanaan kegiatan di lakukan untuk mendukung kelancaran kegiatan sebagai berikut :

1. Mengirim surat kesediaan pemerintah desa jatibaru perihal kesediaannya untuk mengikuti pelatihan.

2. Menerima tanggapan yang cukup antusias dari pemerintahan jati baru atas kesediaannya unttk pelaksanaan kegiatan pengabdian kepada masyarakat pada tanggal 6 s.d 8 Desember 2019, kegiatan pelatihan di mulai dari pukul 08.00 hingga 13.00 dengan susunan acara : a. Peserta menempati ruangan. Peserta kegiatan pengabdian berjumlah 17 orang ibu PKK dan 5 orang pemerintahan desa jatibaru,

3. Pelaksanan, adapun tahapan pelaksanaan dari pengabdian kepada masyarakat ini adalah sebagai berikut

a. Pembukaan oleh ibu kepala desa jati baru ibu sumi helmi barus sekaligus pembuka acara pengabdian kepada masyarakat ini

b. Penyuluhan tentang pengertian teknologi informasi kepada ibu-ibu PKK

c. Penyajian Materi Pembelajaran Pada tahapan ini tim menjelaskan materi-materi yang akan di jelaskan oleh tutor temtang 
1) Internet

2) Internet positif

3) UU ITE

4) Etika ber internet menurut UU ITE

5) Pemanfaatan Media Sosial Sebagai Media Promosi Penjualan

d. Pendampingan praktek dan konsultasi langsung antara tutor dan peserta terkait teknologi informasi.

e. Evaluasi untuk mengetahui dan mengukur daya serap peserta terhadap pelatihan ini

Hasil Kegiatan pengabdian pada masyarakat ini diharapkan akan memberikan kontribusi positif dalam meningkatkan pengetahuan ibu-ibu PKK untuk mengembangkan ilmu pengetahuan tentang komputer. Secara lebih eksplisit manfaat kegiatan ini adalah sebagai berikut: Ibu-ibu PKK Desa Jati Baru memperoleh wawasan tentang pentingnya memiliki pengetahuan tentang penggunaan smartphone, komputer dan internet dalam kehidupan sehari-hari, Ibu-ibu PKK Desa Jati Baru mampu untuk menggunakan smartphone, komputer dan internet untuk mengontrol anak anak mereka dalam penggunaan komputer, smartpone dan internet, Ibu-ibu PKK Desa Jati mampu menggunakan media sosial sebagai sarana promosi dan berniaga untuk mendapatkan keuntungan finansial, Ibu-ibu PKK Desa Jati Baru memperoleh wawasan tentang pentingnya beretika di sosial media dan internet dan mampu memahami konsep dasar undang-undang informasi transaksi elektronik (ITE)

Target dalam kegiatan pengabdian kepada masyarakat ini, yaitu: Warga menjadi termotivasi untuk belajar dan lebih mengerti akan pentingnya ilmu pendidikan penggunaan computer. Membantu mengedukasi ibu-ibu PKK agar bisa mencegah dan mengawasi anak-anaknya dari penggunaan negatif dari komputer, smartphone dan internet. Menciptakan ekonomi kreatif dengan cara memberikan edukasi penggunaan media sosial untuk berniaga. Mampu menjadi pelopor dalam ber etika dalam beretika di media sosial dan internet.

\section{Hasil dan Pembahasan}

Kegiatan Edukasi dan pelatihan pemanfaatan teknologi informasi untuk ibu-ibu PKK dilaksanakan pada tanggal 06 s/d 08 Desember 2019 di Desa Jati Baru kecamatan Pagar Merbau dengan rincian 3x pertemuan dalam 1 minggu. Narasumber dan anggota membagikan materi kepada ibu-ibu PKK tentang pentingnya pemanfaatan teknologi bahkan dalam bidang bisnis serta dampak postif dan negatif dari penggunaan internet.

Realisasi Kegiatan dilakukan dibalai desa dengan ibu PKK sejumlah 15 orang dan perangkat desa 5 orang, kegiatan dilakukan dengan presentase dan tanya jawab, para peserta sangat antusias dan aktif dalam kegiatan tersebut, pemateri menjelaskan dengan baik materi-materi yang diberikan dan selalu memberikan kesempatan tanya jawab dan diskusi.

Berikut adalah foto-foto realisasi dan list presensi kegiatan Pengabdian Kepada Masyarakat Edukasi Dan Pelatihan Pemanfaatan Teknologi Informasi Untuk Ibu-Ibu Pkk Desa Jati Baru. 

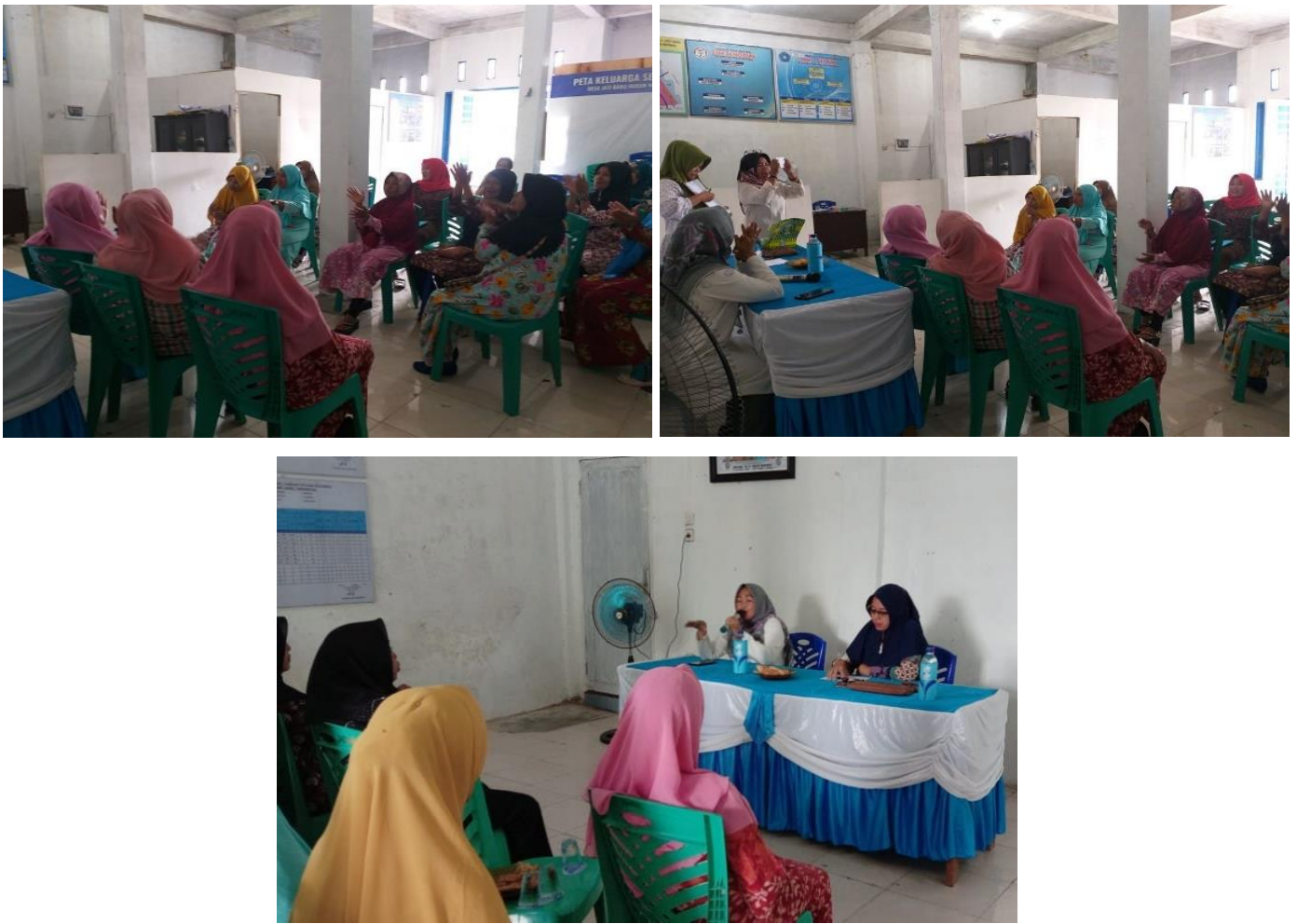

Gambar 1. Realisasi Kegiatan

Adapun luaran yang dicapai pada kegiatan pengabdian kepada masyarakat tentang Edukasi dan pelatihan pemanfaatan teknologi informasi untuk ibu-ibu PKK desa Jati baru adalah ibu-ibu PKK menjadi lebih memahi pemanfaatan teknologi komunikasi, memahami undang undang ITE dan bisa mengoptimalkan dalam pemanfaatan penggunaan handphone android yang dimiliki baik dalam bidang pengawasan kepada anak maupun dalam bidang bisnis seperti bisnis online, dan nantinya laporan pengabdian ini akan dipublikasikan di jurnal nasional.

\section{Kesimpulan}

Kegiatan Edukasi dan pelatihan pemanfaatan teknologi informasi untuk ibu-ibu PKK di Desa Jati Baru Kecamatan Pagar Merbau menjadikan ibu-ibu PKK menjadi lebih optimal dalam memanfaatkan teknologi saat ini serta mengetahui dampak positif dan negatif dari perkembangan teknologi terutama bagi diri sendiri dan anak-anak.

\section{Daftar Pustaka}

Arizona, N. D. (2017). Aplikasi Pengolahan Data Anggaran Pendapatan dan Belanja Desa ( APBDES ) Pada Kantor Desa Bakau Kecamatan Jawai Berbasis Web, 01(02), 105119.

Simarmata, Janner.(2010). Rekayasa Web. Yogyakarta:Andi. 2014.

Slamet, Margono. (2000). Memantapkan Posisi dan Meningkatkan Peran Penyuluhan Pembangunan dalam Pembangunan. Dalam Proseding Seminar IPB Bogor: 
Pemberdayaan Sumber Daya Manusia Menuju Terwujudnya Masyarakat Madan. Pustaka Wira Usaha Muda.

Sudjana, Nana. (2004). Dasar-dasar Proses Belajar Mengajar. Bandung :Sinar Baru Algensido Offset.

Undang-Undang Republik Indonesia Nomor 11 Tahun 2008 Tentang Informasi Dan Transaksi Elektronik 